\title{
Overaccumulation of the chloroplast antisense RNA AS5 is correlated with decreased abundance of $5 S$ rRNA in vivo and inefficient $5 S$ rRNA maturation in vitro
}

\author{
ROBERT E. SHARWOOD, AMBER M. HOTTO, THOMAS J. BOLLENBACH, ${ }^{1}$ and DAVID B. STERN \\ Boyce Thompson Institute for Plant Research, Ithaca, New York 14853, USA
}

\begin{abstract}
Post-transcriptional regulation in the chloroplast is exerted by nucleus-encoded ribonucleases and RNA-binding proteins. One of these ribonucleases is RNR1, a 3'-to-5' exoribonuclease of the RNase II family. We have previously shown that Arabidopsis rnr1-null mutants exhibit specific abnormalities in the expression of the rRNA operon, including the accumulation of precursor 23S, 16S, and 4.5S species and a concomitant decrease in the mature species. 5S rRNA transcripts, however, accumulate to a very low level in both precursor and mature forms, suggesting that they are unstable in the rnr1 background. Here we demonstrate that rnr1 plants overaccumulate an antisense RNA, AS5, that is complementary to the 5S rRNA, its intergenic spacer, and the downstream $\operatorname{trn} R$ gene, which encodes tRNA ${ }^{\text {Arg }}$, raising the possibility that AS5 destabilizes $5 S$ rRNA or its precursor and/or blocks rRNA maturation. To investigate this, we used an in vitro system that supports 5S rRNA and trnR processing. We show that AS5 inhibits 5S rRNA maturation from a 5S-trnR precursor, and shorter versions of AS5 demonstrate that inhibition requires intergenic sequences. To test whether the sense and antisense RNAs form double-stranded regions in vitro, treatment with the single-strand-specific mung bean nuclease was used. These results suggest that $5 \mathrm{~S}-\mathrm{AS} 5$ duplexes interfere with a sense-strand secondary structure near the endonucleolytic cleavage site downstream from the 5S rRNA coding region. We hypothesize that these duplexes are degraded by a dsRNA-specific ribonuclease in vivo, contributing to the $5 S$ rRNA deficiency observed in rnr1.
\end{abstract}

Keywords: chloroplast; antisense RNA; RNA processing; ribosomal RNA

\section{INTRODUCTION}

The chloroplast is derived from a prokaryotic ancestor, and its residual genome is expressed through a combination of prokaryotic and acquired eukaryotic mechanisms. Prokaryotic ancestry is reflected in gene organization, transcriptional mechanisms, and by the presence of numerous bacterial-like enzymes, including a suite of ribonucleases (RNases). On the other hand, the prevalence of introns, RNA editing, and their associated trans-acting factors are not found in prokaryotes (for review, see Stern et al. 2010).

One of the conserved ancestral features of the chloroplast is its ribosomal RNA operon, which consists of four rRNA

${ }^{1}$ Present address: Organogenesis, Inc., 150 Dan Road, Canton, MA 02021, USA.

Reprint requests to: David B. Stern, Boyce Thompson Institute for Plant Research, Tower Road, Ithaca, New York 14853, USA; e-mail: ds28@ cornell.edu; fax: (607) 254-6779.

Article published online ahead of print. Article and publication date are at http://www.rnajournal.org/cgi/doi/10.1261/rna.2336611. genes and three tRNA genes in the order rrn16-trnI-trnArrn23-rrn4.5-rrn5-trnR, with the first two tRNA genes containing introns. A full-length precursor is transcribed from a promoter proximal to rrn16 (Strittmatter et al. 1985), and the individual transcripts are liberated from the primary transcript through tRNA processing by RNases $\mathrm{P}$ and $\mathrm{Z}$ (Canino et al. 2009; Gobert et al. 2010), followed by additional endonucleolytic cleavages and exonucleolytic trimming of the rRNAs. Finally, processing of two so-called hidden breaks occur within 23S rRNA after its incorporation into the ribosome (Leaver 1973).

While the endonucleases that cleave between 23S, 4.5S, and $5 \mathrm{~S}$ rRNAs remain to be identified, two exonucleases that participate in rRNA maturation have been characterized. Depletion of polynucleotide phosphorylase (PNPase) results in $3^{\prime}$-end extension of $23 \mathrm{~S}$ rRNA (Walter et al. 2002), and the absence of ribonuclease R (RNR1) leads to $3^{\prime}$ extensions of $10 \mathrm{nt}$ or less for 23S, 16S, 4.5S, and 5S rRNAs (Bollenbach et al. 2005). Because wild-type (WT) 3' ends also accumulate for $5 \mathrm{~S}$ rRNA in the $r n r 1$ mutant, it is likely 
that in this instance PNPase can partially substitute for RNR1.

One intriguing feature of the rnr1 mutant is its 5S rRNA phenotype. Unlike the other rRNAs, where precursors accumulate at the expense of mature forms, all forms of $5 \mathrm{~S}$ rRNA accumulate to very low levels (Bollenbach et al. 2005). Since the operon is transcribed from a single promoter, either the precursor and/or mature 5S rRNAs must be unstable in the mutant. Because instability of organellar transcripts is often associated with their polyadenylation (for review, see Schuster and Stern 2009), we decided to search the EST databases for polyadenylated forms of $5 \mathrm{~S}$ rRNA, to see if there was any evidence that it was degraded by this pathway in WT plants, as polyadenylated chloroplast 5S rRNA had previously been found in Chlamydomonas using RT-PCR (Komine et al. 2000). EST databases can contain cDNAs corresponding even to unstable transcripts, as was demonstrated for human mitochondrial polyadenylation (Slomovic et al. 2005). In the case of chloroplast $5 S$ rRNA, ESTs corresponding to a polyadenylated form were not found. Surprisingly, however, we found a number of ESTs corresponding to the antisense strand of the rrn5-trnR region of the rRNA operon (see Results). We refer collectively to these ESTs and related transcripts as AS5 (for antisense to $\underline{5} \mathrm{~S}$ ).

Antisense RNAs (asRNAs) are common in prokaryotes and can regulate RNA processing, RNA stability, and translation both in cis and trans (for review, see van Vliet and Wren 2009; Waters and Storz 2009). In chloroplasts, a few asRNAs have been found by bulk sequencing of small RNAs (Lung et al. 2006), and another was found through an informatics-based strategy (Georg et al. 2010). While functions of natural chloroplast asRNAs, including AS5, remain to be elucidated, artificial asRNAs can affect chloroplast gene expression. In one case a polyadenylated transcript in Chlamydomonas was stabilized by asRNA transcription from a convergent promoter (Nishimura et al. 2004), and in another case an asRNA interfered with C-to-U RNA editing in tobacco (Hegeman et al. 2005). In this study, we show that AS5 overaccumulates in the rnr1 mutant, offering a possible basis for reduced 5S rRNA (sense strand) accumulation. We have tested this hypothesis using an in vitro system and show that regions of sense-antisense base-pairing may block a step in $5 \mathrm{~S}$ rRNA maturation, while forming a duplex that is subject to degradation.

\section{RESULTS}

\section{Altered accumulation of $5 \mathrm{~S}$ rRNA and tRNA ${ }^{\text {Arg }}$ in $r n r 1-3$}

As mentioned above, the rnrl mutant is deficient in $5 \mathrm{~S}$ rRNA. Figure 1A shows that in WT plants, $5 \mathrm{~S}$ rRNA accumulates almost exclusively as the mature 121-nt transcript. In the null allele rnr1-3, however, additional forms of $5 \mathrm{~S}$ can be seen. One is several nucleotides longer than the

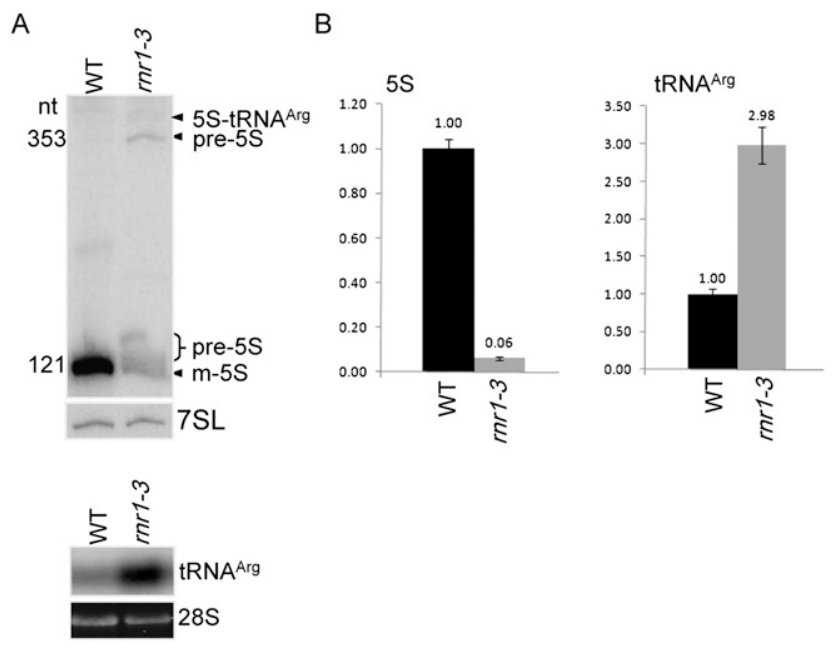

FIGURE 1. Accumulation and processing of $5 \mathrm{~S}$ rRNA and tRNA ${ }^{\mathrm{Arg}}$ in $r n r 1-3$. (A) RNA gel blot of $0.5 \mu \mathrm{g}$ total RNA extracted from wildtype (WT) and rnrl-3 rosette leaves, probed for 5S rRNA (upper panel) and tRNA ${ }^{\mathrm{Arg}}$ (lower panel). RNA loading is represented by 7SL, an snRNA (upper panel) and ethidium bromide staining of the $28 \mathrm{~S}$ rRNA (lower panel). Transcript sizes are indicated at left, and RNA species are designated at right. (B) Quantitative RT-PCR determination of 5S rRNA and tRNA ${ }^{\text {Arg }}$ abundance. Expression levels are an average of three biological and at least two technical replicates for each sample, with error bars representing the standard deviation. The WT expression level was set to 1 , and samples were normalized to actin mRNA.

mature transcript and represents incomplete exonucleolytic trimming, as previously documented by cDNA sequencing (Bollenbach et al. 2005). The 353-nt form represents 5S rRNA plus the intergenic region up to the $\operatorname{trnR} \mathrm{RNase} \mathrm{P}$ cleavage site, and still higher on the gel are longer precursors that do not resolve. The collective amount of precursors and the abundance of mature 5S rRNA in the mutant are comparable, while the mature form is deficient compared to the WT. In contrast, the accumulation of tRNA ${ }^{\text {Arg }}$ in rnrl-3 exceeds the WT level (Fig. 1A, lower). Thus, absence of RNR1 has opposite consequences for the transcripts from two adjacent genes.

Figure 1B shows quantitative RT-PCR (qRT-PCR) analysis for $r r n 5$ and $t r n R$. It was found that $r n r 1-3$ contains $6 \%$ of the WT rrn5 transcripts. Because the primer pair used amplifies both precursor and mature forms, the mature $5 \mathrm{~S}$ rRNA accumulates to $\sim 3 \%$ of the WT level. In agreement with gel blot analysis, qRT-PCR showed that trnR overaccumulates in rnrl-3 by approximately threefold. These quantitative data confirm the effects of RNR1 deficiency on these two RNA species.

\section{rrn5-trnR antisense RNAs accumulate in rnr1-3}

As mentioned in the Introduction, ESTs corresponding to the antisense strand of the $r r n 5$-trnR region were discovered while searching for polyadenylated versions of $5 \mathrm{~S}$ rRNA. Representative ESTs from Arabidopsis are shown in 
Figure $2 \mathrm{~A}$, as related to a map of the distal portion of the rRNA operon and the convergently transcribed downstream $\operatorname{trnN}$ gene. We used qRT-PCR to confirm and quantify the presence of AS5 from WT and rnr1-3. The left panel of Figure 2B shows that AS5 was roughly ninefold more abun-

A

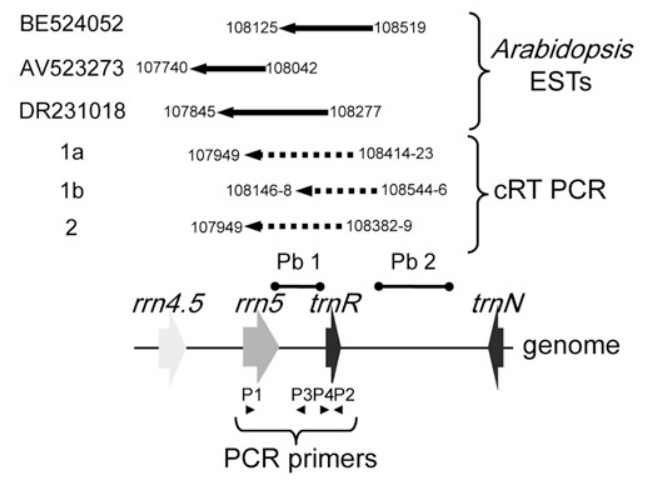

B
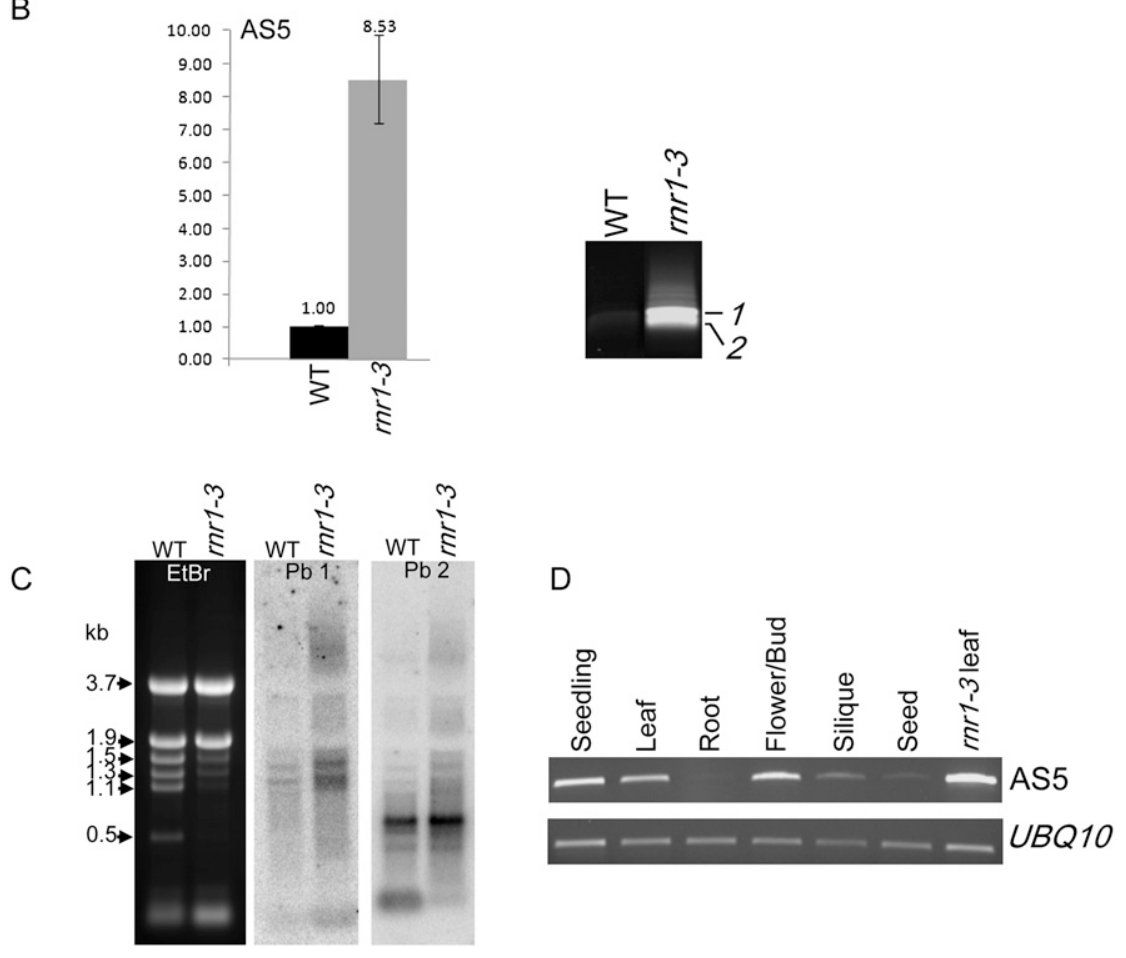

FIGURE 2. Identification and accumulation of asRNAs complementary to 5S-trnR in wildtype (WT) and rnrl-3 plants. (A) Representative ESTs corresponding to the antisense strand of the 5S-trnR region. The major AS5 species identified in rnr1-3 from sequencing of cRT-PCR products are indicated by dotted lines, with the $5^{\prime}$ and $3^{\prime}$ ends numbered according to the Arabidopsis chloroplast genome. PCR primer annealing positions are indicated by arrowheads, and the strand-specific probes used in $C$ are shown above ( $\mathrm{Pb} 1$ and $\mathrm{Pb} 2)$. (B) AS5 accumulation was determined by qRT-PCR (left) as described in the legend to Figure 1. cRT-PCR (right) was used to amplify cDNAs for $5^{\prime}$ and $3^{\prime}$ end determination. Bands 1 and 2 refer to the sequences shown in panel $A$. (C) Agarose gel blot analysis of AS5 using $15 \mu \mathrm{g}$ of total RNA. The probes used are indicated at the top of each gel, with the gene location shown in $A$. The ethidium bromide-stained gel (left) is shown to reflect loading. Sizes in kilobases correspond to known rRNA species. $(D)$ Amplification of AS5 by RT-PCR from WT tissues, and rnrl-3 (last lane on right). Ubiquitin was used as a control. dant in rnr1-3. Thus, an increase in AS5 is correlated with a decrease in the cognate sense-strand transcript insofar as $S$ rRNA is concerned.

To map the species of AS5 present in rnr1-3, DNase I-treated total RNA was circularized, and AS5-specific cDNA was generated using primer P4 (Fig. 2A). Subsequent amplification using primers $\mathrm{P} 3$ and $\mathrm{P} 4$ resulted in two major amplicons (Fig. 2B, right panel) that were more abundant in $r n r 1-3$ than in the WT, consistent with the qRTPCR results. Each of the amplicons was sequenced, and three RNA species were identified as shown below the gene diagram, that range from 400 to $474 \mathrm{nt}$ (Fig. 2A). Amplicons 1a and 1b were of similar size but displaced; their $3^{\prime}$ ends corresponded to the $5^{\prime}$ and $3^{\prime}$ ends of mature 5S rRNA, respectively, albeit on the opposite strand. Amplicon 2 also had a $3^{\prime}$ end corresponding to the rrn5 $5^{\prime}$ end, while its $5^{\prime}$ end corresponded to a position just downstream from trnR. Thus, the term "AS5" refers to a collection of transcripts from the $5 \mathrm{~S}-\mathrm{trn} R$ region, but all include the intergenic region where the first step of 5S rRNA $3^{\prime}$-end maturation occurs. In agreement with this heterogeneity, RNA gel blot analysis revealed three major bands, all of which were more abundant in $r n r 1-3$ (Fig. 2C). These 1.1-1.5-kb RNAs are larger than those defined by ESTs; however, we presume that the ESTs are clones of polyadenylated degradation intermediates, and thus are likely to be incomplete fragments of intact AS5 transcripts, or incompletely sequenced cDNAs (see Discussion). To determine whether these AS5 transcripts might initiate downstream from $t r n R$, a strand-specific probe corresponding to the trnR-trnN intergenic region was used $(\mathrm{Pb} 2)$. This probe identified the same transcripts, as well as a species of $\sim 600 \mathrm{nt}$ that was also more abundant in rnr1-3. Whether any or all of these transcripts initiate from the $\operatorname{trnN}$ promoter remains to be elucidated.

To determine whether AS5 accumulates in a tissue-specific manner, RT-PCR was used to amplify AS5 from various tissues of WT plants, as shown in Figure 2D. AS5 accumulates in seedlings, leaves, and inflorescences, but was barely detectable in roots and seeds. The pattern 
of higher expression in green tissues is consistent with that of light-regulated transcripts encoding photosynthetic components. In addition, both chloroplast rRNA synthesis (e.g., Ingle 1968) and translation (for review, see Mullet 1988) are stimulated by light. Whether AS5 has any role in light regulation of the translational apparatus remains to be determined.

\section{In vitro inhibition of $5 S$ rRNA maturation by AS5}

The data shown above correlate increased AS5 accumulation with decreased 5S rRNA accumulation, raising the possibility of a causal relationship. To test this hypothesis in a defined system, we took advantage of a spinach chloroplast stromal extract that had been previously used to dissect transcription initiation (Gruissem and Zurawski 1985a,b), mRNA maturation (Stern and Gruissem 1989; Schuster and Gruissem 1991; Kudla et al. 1996), and tRNA processing (Gruissem et al. 1983; Stern and Gruissem 1987). Equivalent Arabidopsis extracts have not been characterized, but the two dicotyledenous plants are expected to have similar or identical complements of chloroplast RNA processing components. To confirm that $5 \mathrm{~S}$ rRNA processing occurs in this extract, we incubated a radiolabeled transcript corresponding to the $5 \mathrm{~S}$ coding region, the flanking intergenic region, and the downstream $\operatorname{trn} R$ gene. This substrate is diagrammed at the top of Figure $3 \mathrm{~A}$, and the reaction products are shown in the left lane of Figure 3B. Four major bands are seen at the end of the time course: the residual full-length 5S-trnR substrate of 427 nt, a 353-nt band corresponding to the precursor lacking trnR following RNase $\mathrm{P}$ cleavage, the mature $5 \mathrm{~S}$ rRNA of $121 \mathrm{nt}$, and the 74-nt mature tRNA ${ }^{\text {Arg }}$.

To see whether AS5 could affect 5S rRNA maturation or stability in vitro, we initially chose to test an AS5 form that closely corresponded to one of those confirmed by cRTPCR (Fig. 2A). Form 1a has its $5^{\prime}$ end at the $3^{\prime}$ end of trnR, and its $3^{\prime}$ end coincides with the $5^{\prime}$ end of the mature $5 \mathrm{~S}$ rRNA. The in vitro version of this asRNA was named AS5-1. Figure $3 \mathrm{~B}$ shows a representative experiment in which increasing amounts of AS5-1 were incubated with the sense transcript, followed by addition of chloroplast extract. The asRNAs were trace-labeled ( $\sim 0.02 \%$ of the specific activity of the sense transcript) and become visible in the gel at a 50-fold or higher excess (see labels to right of gel; AS5-1 co-migrates with the sense-strand precursor). We observed a decrease in 5S rRNA production between 50- and 100fold molar excess of AS5-1, and a less pronounced decrease in the production of $\mathrm{tRNA}^{\mathrm{Arg}}$. This result demonstrates that in vitro, an RNA akin to AS5 can inhibit 5S rRNA maturation, with a lesser effect on $\mathrm{RNA}^{\mathrm{Arg}}$. At the same time, we observed an increase in diffuse RNA accumulation in the higher-molecular-weight region of the gel. We suspected that these might represent heterodispersed species generated through degradation of RNA duplexes. The formation of duplexes is explored further below.

A second asRNA, AS5-2, corresponding only to the rrn5$\operatorname{trn} R$ intergenic region, was used to determine whether any effect of AS5-1 was due to the complementarity to coding regions versus intergenic sequences. As the amount of AS5-2 was increased, we observed no effect on tRNA ${ }^{\text {Arg }}$ production; however, a decrease in 5S rRNA accumulation became evident when the inhibitor was added in a 250 -fold or higher excess (Fig. 3B). This suggests that while the decrease in $\mathrm{tRNA}^{\mathrm{Arg}}$ production was due to pairing of the asRNA to the trn $R$ coding region, intergenic sequences contributed to the effect of AS5-2 on 5S rRNA accumulation. Because AS5-2 was less effective than AS5-1 at higher asRNA concentrations, the antisense $5 \mathrm{~S}$ coding region also plays a role.

To gain more insight into the AS5 sequences that were critical for in vitro inhibition of $5 \mathrm{~S}$ rRNA production, we 
used several additional substrates, as diagrammed in Figure 4A. AS5-3 corresponds to the sequence antisense to rrn5, whereas AS5-4 contains the antisense intergenic region as well. AS5-5, AS5-6, and AS5-7 are similar sequences differing with respect to RNA processing sites on the sense strand. AS5-5 and AS5-7 have 3' ends 78 nt downstream from the mature 5S rRNA $3^{\prime}$ end. The sense-strand intergenic region, including the region not overlapped by AS5-5 and AS5-7, is believed to include endonucleolytic cleavage sites that generate substrates for exonucleolytic trimming to the mature 5S 3' end (Leal-Klevezas et al. 2000). AS5-5 and AS5-7 differ in that AS5-5 contains sequences antisense to the tRNA ${ }^{\text {Arg }}$ RNase P cleavage site. On the other hand, AS5-6 includes complementarity to all sequences downstream from $r r n 5$ to 19 nt upstream of the trnR RNase P cleavage site.

In vitro experiments using these substrates are shown in Figure $4 \mathrm{~B}$. AS5-3 did not affect tRNA ${ }^{\text {Arg }}$ processing but did

A

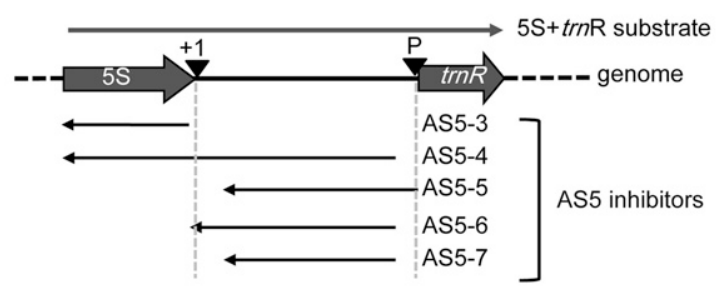

B
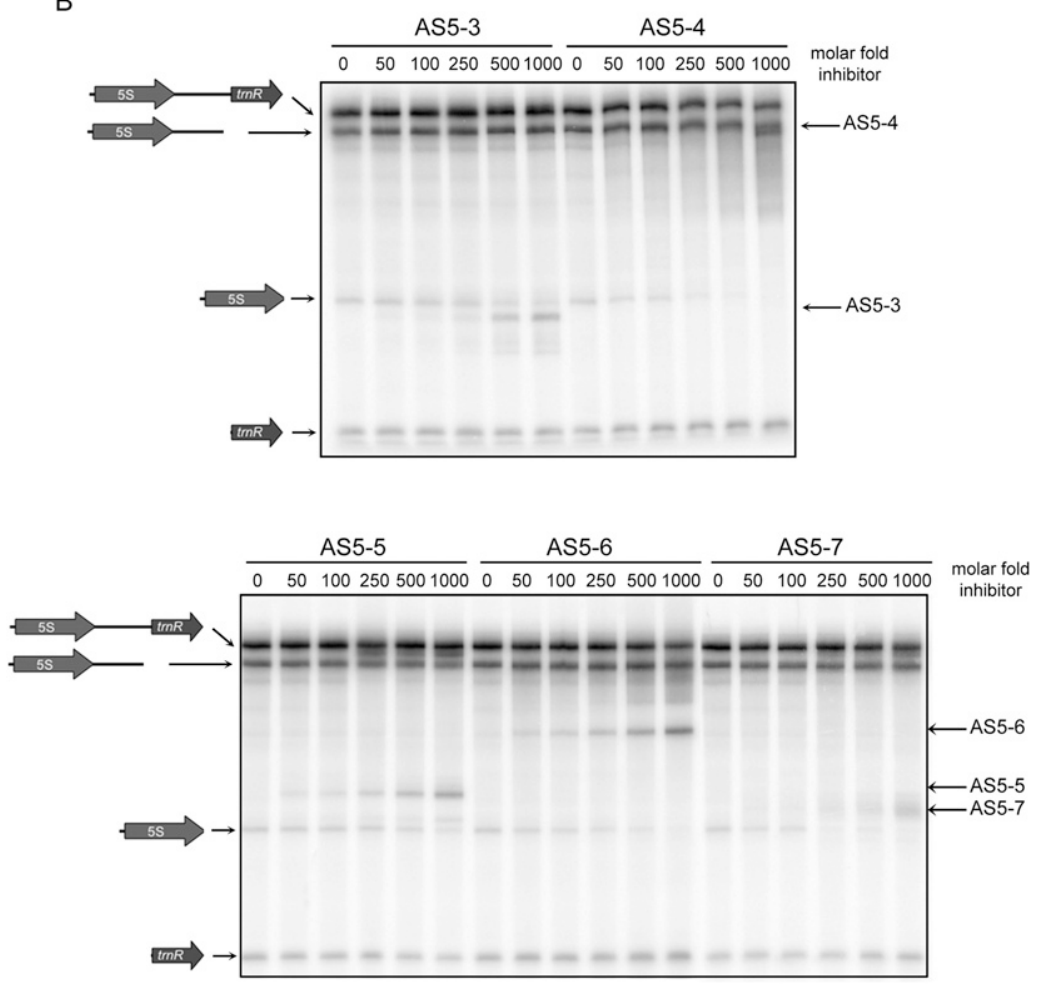

FIGURE 4. AS5 sequence determinants for inhibition of $5 \mathrm{~S}$ rRNA maturation. (A) Representation of sense and antisense substrates, as described in the legend to Figure 3. $(B)$ Processing of labeled 5S-trnR in the absence or presence of antisense inhibitors, as described in the legend to Figure 3. cause a decrease in $5 \mathrm{~S}$ rRNA production when added in a 500-fold or greater excess. Thus, sequences antisense to the $r r n 5$ coding region are a less effective inhibitor than the antisense intergenic region (AS5-2) (Fig. 3B). AS5-4 was a very effective inhibitor, demonstrating again the importance of the antisense intergenic region. AS5-5 was less effective than AS5-6 at inhibiting 5S rRNA maturation, suggesting that overlap with the putative endonuclease cleavage sites may inhibit cleavage. On the other hand, AS5-7, which like AS5-5 lacks RNA antisense to the endonuclease cleavage region, was a better inhibitor than AS5-5. It is possible that an AS5-7 sense-strand duplex forms more readily than an AS5-5 sense-strand duplex, a hypothesis that remains to be tested.

The extents of inhibition of 5S rRNA and tRNA ${ }^{\text {Arg }}$ processing by different forms of AS5 are presented in Figure 5, A and B, respectively. In the case of AS5-1, reduction of $5 \mathrm{~S}$ rRNA yield decreased from $75 \%$ to $25 \%$ with increasing amounts of asRNA added. Slightly more effective at inhibiting 5S rRNA maturation than AS5-1 was AS5-4, which lacks sequences complementary to $\operatorname{trn} R$ and its associated RNase P site. Of the molecules identified in vivo, EST AV523273 most closely corresponds to this sequence. AS5-2 and AS5-7 were approximately half as effective as AS5-1 and AS5-4 at preventing 5S processing. Thus, it can be tentatively concluded that sequences antisense to the coding and intergenic regions each contribute similar portions of the inhibitory effect. On the other hand, only AS5-1 inhibited tRNA $^{\text {Arg }}$ yield, this being the only asRNA competitor with complementarity to the tRNA coding region.

\section{AS5 effects on 5S-trnR processing intermediates}

As mentioned above, 5S rRNA maturation proceeds through several intermediates. To see whether these forms were differentially susceptible to asRNA inhibition of maturation, we tested each of them in vitro with three representative AS5 RNAs. One form corresponded to the rrn5 precursor after RNase $\mathrm{P}$ cleavage, a substrate we term $5 \mathrm{~S}+\mathrm{I}$ (rrn5 plus the downstream intergenic region). There are also probable endonucleolytic cleavages at least 10 nt downstream from the mature $3^{\prime}$ end, based on the forms that accumulate in $r n r l$ 
A

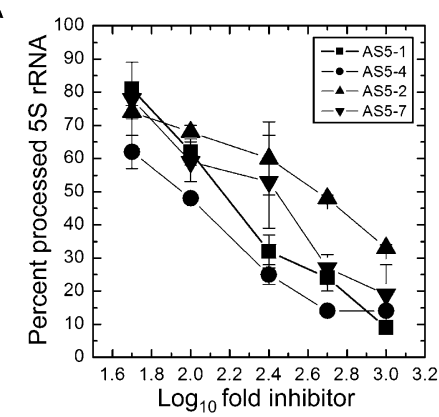

B

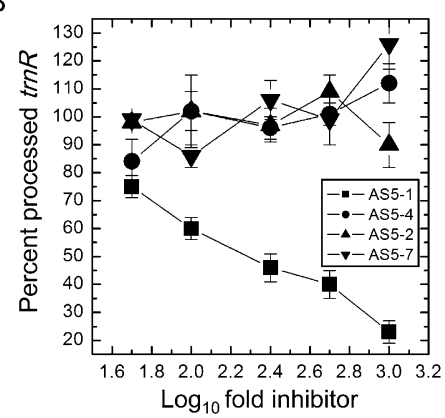

FIGURE 5. Quantitative measurement of inhibition of $5 \mathrm{~S}$ rRNA $(A)$ and tRNA ${ }^{\operatorname{Arg}}(B)$ maturation by AS5 substrates. The signal intensity of the mature transcripts ( $y$-axis) was plotted against $\log _{10}$ (fold excess of inhibitor used) ( $x$-axis). Linear regressions were fitted to each data set to determine inhibition efficiency. $100 \%$ processing efficiency was defined as 5S rRNA or tRNA ${ }^{\text {Arg }}$ yield without inhibitor.

mutants (Bollenbach et al. 2009), and these products are trimmed exonucleolytically. The form $5 \mathrm{~S}+33$ was created to mimic a putative substrate for endonucleolytic cleavage and/or exonucleolytic trimming. These two intermediates were compared to mature $5 \mathrm{~S}$ rRNA and the full-length 5StrnR precursor used above.

Figure 6A shows results for AS5-1. Addition of this asRNA had no obvious effect on mature 5S rRNA, suggesting that in the rnrl mutant a $5 \mathrm{~S}$ precursor is the most likely target of AS5. On the other hand, while $5 S+33$ could be matured correctly in the presence of AS5-1, both the efficiency and the yield of the reaction were reduced. Since the rnr1 mutant does accumulate small amounts of mature 5S rRNA, it is likely processed from an endonucleolytically cleaved form by PNPase, which is known to be inhibited by dsRNA (Yehudai-Resheff et al. 2001). Both $5 S+I$ and the full-length precursor were strongly inhibited by AS5-1 in terms of 5S rRNA production, again showing that the endonucleolytic cleavage step is particularly sensitive to asRNA.

When AS5-4 (antisense of 5S + I) was used as an inhibitor with the different sense forms (Fig. 6B), the results were similar to those observed for AS5-1. The coherence of the AS5-1 and AS5-4 results was expected, since they only differ with respect to the presence of antisense $\operatorname{trn} R$ sequences. When AS5-7 was tested (Fig. 6C), no significant effects on mature $5 \mathrm{~S}$ rRNA stability or maturation of $5 \mathrm{~S}+33$ were seen. However, AS5-7 did affect 5S rRNA production when the $5 \mathrm{~S}+\mathrm{I}$ or $5 \mathrm{~S}-\mathrm{trnR}$ forms were tested. This result suggests that endonucleolytic cleavage steps are the major target of AS5. In contrast, the asRNA transcript complementary to mature 5S (AS5-3) had little or no effect on any of the sense forms (Supplemental Fig. S1), indicating the importance of the intergenic region for AS5 activity.

If AS5 is inhibiting 5S (and, to some extent, $\mathrm{tRNA}^{\mathrm{Arg}}$ ) production through base-pairing rather than a general inhibition of RNA processing activities, two predictions should be fulfilled. One is that adding an excess of an RNA unrelated to $5 S$-trnR should not inhibit 5S rRNA production. To this end, we tested the $3^{\prime}$-end maturation of the chloroplast petD mRNA, which is thought to be trimmed by a combined endo- and exonucleolytic mechanism (Stern and Gruissem 1987; Hayes et al. 1996), in the presence of $5 S-\operatorname{trn} R$. We found that even a 1000 -fold excess of the petD precursor not only had a very mild effect on 5S rRNA production, but was also itself processed efficiently (Supplemental Fig. S2). This suggests that under

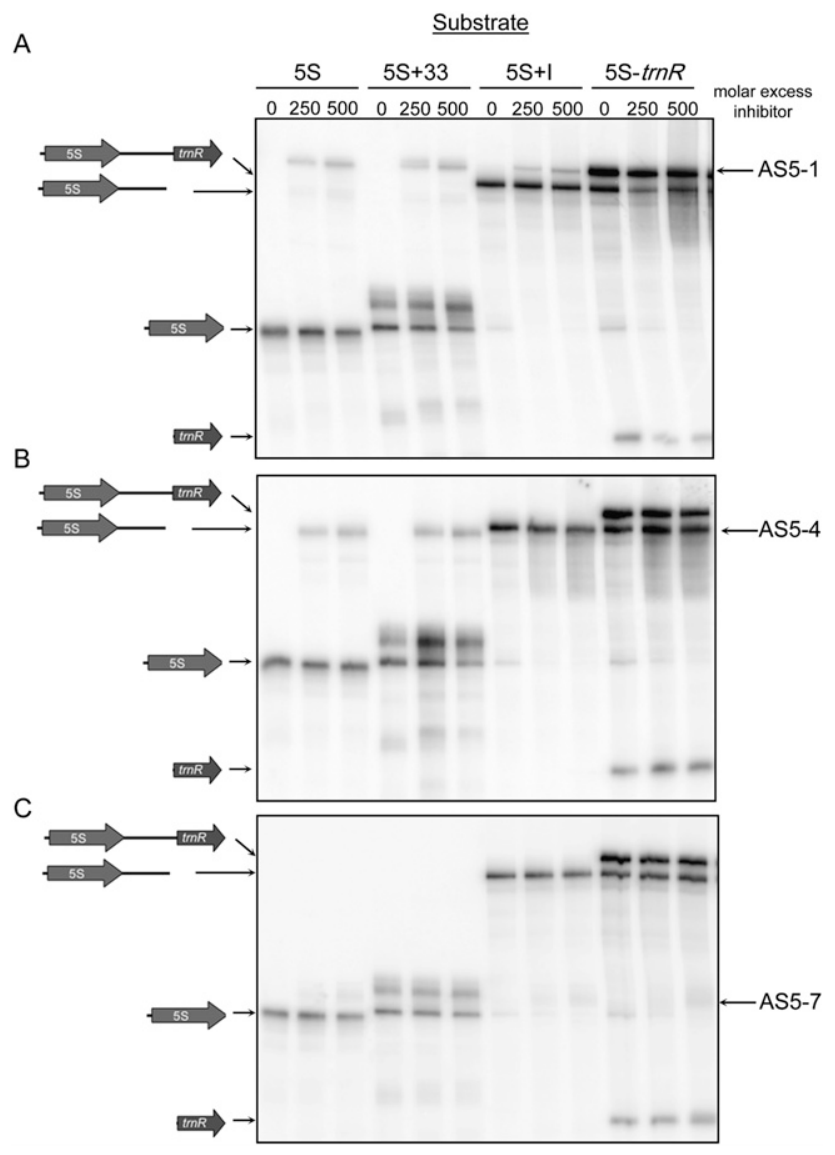

FIGURE 6. Effect of AS5 inhibitors on the stability of mature $5 \mathrm{~S}$ rRNA or various processing intermediates. The labeled intermediates were mature 5S rRNA (5S), a 33-nt extended precursor $(5 S+33)$, a 232-nt extended precursor $(5 \mathrm{~S}+\mathrm{I})$, and the complete $5 \mathrm{~S}-\mathrm{trn} R$ substrate. Increasing amounts of AS5-1 $(A)$, AS5-4 (B), and AS5-7 (C) were used with electrophoresis as described in the legend to Figure 3. 
the conditions used, limiting enzyme is not responsible for the observed results. A second prediction is that dsRNA segments should form between AS5 and the sense substrate, if, indeed, 5S rRNA maturation is inhibited through intermolecular interactions. This was investigated as shown immediately below.

\section{Formation of dsRNA during the in vitro reaction}

Both $r r n 5$ and $t r n R$, as well as the intergenic region, would be expected to form highly conserved secondary structures (Leal-Klevezas et al. 2000). In addition, bacterial rRNA intergenic regions form intramolecular base pairs that are recognized by RNase III (Srivastava and Schlessinger 1990). Very likely, AS5 would interfere with that folding by binding to different forms of 5S rRNA, thereby preventing maturation. To test for the formation of dsRNA, we used mung bean nuclease $(\mathrm{MBN})$, which specifically cleaves ssRNA in a sequence-independent manner. To do so, we extracted RNA under native conditions following in vitro RNA processing, to preserve dsRNA while eliminating RNA binding proteins that might protect ssRNA from $\mathrm{MBN}$ cleavage.

On the left side of Figure 7B (- lanes), results are shown for processing reactions not treated with MBN. These mirror the results shown earlier for each asRNA (Figs. 3, 4; see Fig. 7A for AS5 inhibitor extents), such as the strong inhibition of 5S rRNA production by

AS5-1 and AS5-4. Aliquots of the same reactions treated with $\mathrm{MBN}$ are on the right side of Figure 7B (+ lanes). When no AS5 inhibitor was present, the sense RNA was almost entirely degraded. In the case of AS5-1, we saw protection of a full-length duplex (labeled $\mathrm{F}$ ), as well as six major protected species: two single bands (labeled A and B) estimated to be $350 \mathrm{nt}$ and $300 \mathrm{nt}$, respectively; a doublet (labeled C) of $\sim 240 \mathrm{nt}$ and $160 \mathrm{nt}$; two clusters of bands (labeled D and E) centered around $160 \mathrm{nt}$ and $120 \mathrm{nt}$, respectively; and a single band (labeled G) of $\sim 90$ nt. Each of these bands will be discussed in terms of whether it, or an apparently related version, was seen when a different AS5 inhibitor was used. It is important to remember that because only the sense strand is labeled, the protected species are derived from the sense RNA. To aid in assigning bands, the experiment was repeated with 5 '-end-labeled 5S-

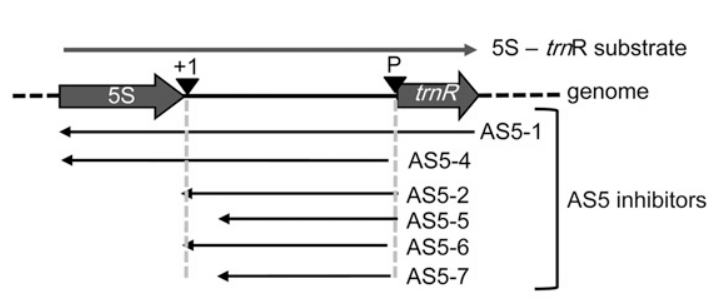

B $\mathrm{C}+$
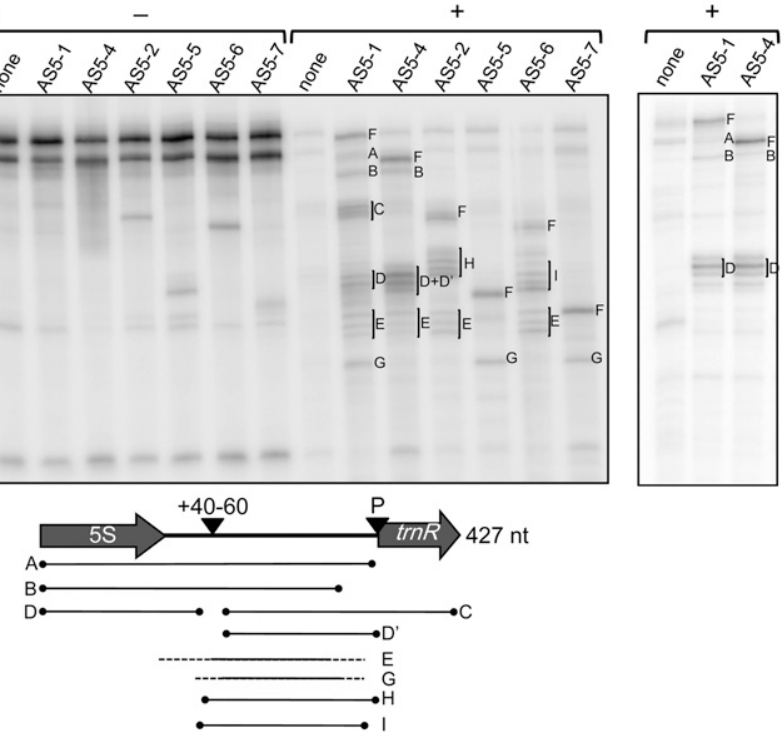

FIGURE 7. Mapping intermolecular base-pairing between $5 S$ - $\operatorname{trnR}$ and AS5 by treatment with mung bean nuclease. ( $A$ ) Representation of the substrates used for the experiment in panels $B$ was incubated with the chloroplast protein extract in duplicate with or without a 500-fold nuclease following RNA purification, and analyzed by $5 \%$ denaturing polyacrylamide gel electrophoresis. (A-I) Transcripts referred to in the text and in panel $D$, with F representing the putative full-length sense-antisense duplex for each AS5 inhibitor. Where clusters of bands and incubated with chloroplast protein extract with or without a 500-fold excess of the two bands seen in panels $B$ and $C$, as discussed in the text. (+40-60) The region of discontinuity susceptible to MBN digestion.

$\operatorname{trnR}$, using the two inhibitors that overlap its $5^{\prime}$ end and thus might conceivably protect the label (Fig. 7C).

As expected, each AS5 inhibitor produced a band F that is the correct size for a full-length or near-full-length duplex. This indicates that zipping up of the duplexes can compete with intramolecular base-pairing. Band $\mathrm{A}$ is the size of $5 \mathrm{~S}+\mathrm{I}$, and is likely to be a duplex lacking $\operatorname{trn} R$ sequences. This may form when RNase $\mathrm{P}$ cleavage precedes sense-antisense interaction. Band B (and the equivalent band for AS5-4) contains most of $5 \mathrm{~S}+\mathrm{I}$, probably having been trimmed at the $3^{\prime}$ end prior to sense-antisense pairing. The assignments of bands $\mathrm{A}$ and $\mathrm{B}$ are strengthened by the fact that they also appear when the sense substrate is 5 '-end-labeled (Fig. 7C).

Cluster D is the other major species that also appears in the 5 '-end-labeling experiment. Therefore, based on its size 
of $160 \mathrm{nt}$, the $3^{\prime}$ ends of the protected species lie 40-60 nt downstream from the mature $5 \mathrm{~S}$ rRNA $3^{\prime}$ end. Based on their sizes and their lack of $5^{\prime}$-end labeling, $C, D^{\prime}, H$, and I represent the distal fragments from a putative $\mathrm{MBN}$ cleavage in the $+40-60$ region. In other words, cluster D and the downstream bands could represent two products of MBN cleavage at a region of discontinuity in a senseantisense duplex, e.g., where intra- rather than intermolecular base-pairing was occurring, leading to the formation of a stem-loop sensitive to MBN. Because the products of this putative MBN cleavage occur in clusters, it is likely that base-pairing is relatively unstable toward the ends of the duplexed regions, leading to "nibbling" by MBN. While proximal cleavage products should also be generated with AS5-2 and AS5-6, these would be very short and thus not visible in our gel system.

Two species remain, whose assignments are ambiguous. These are the bands denoted E and G. The tentative positions depicted in Figure $7 \mathrm{D}$ are based on the assumption that the band is actually the same sequence when seen in different lanes (e.g., band G for AS5-1, AS5-5, and AS5-7). Given this assumption, bands $\mathrm{E}$ and $\mathrm{G}$ may be derived from cleavage in the $+40-60$ region at their $5^{\prime}$ ends, and at a duplex discontinuity upstream of the RNase P site at their $3^{\prime}$ ends. Why these products are not seen in every case where they could theoretically be produced (e.g., band G for AS5-6) is not clear, but may be related to the folding peculiarities of each AS inhibitor.

In summary, the MBN cleavage patterns seen in Figure 7B lead to two conclusions. First, for each AS5 inhibitor, at least a small amount of fully paired duplex is forming. Second, based on the inferred endpoints of smaller protected fragments, there is a strong impetus for intramolecular basepairing to form in the $+40-60$ region in the presence of AS5, leading to formation of a single-stranded region that is susceptible to MBN. Indeed, as more of these MBN-resistant fragments accumulate (right side of Fig. 7B), less mature $5 \mathrm{~S}$ rRNA accumulates (corresponding lanes in left side of Fig. 7B). We conclude that while the $+40-60$ region may still fold correctly in the presence of AS5 and thus be prone to $\mathrm{MBN}$ cleavage, nearby regions are trapped in dsRNA structures that prevent proper sense-strand processing. A model that takes these results into account is presented in the Discussion.

\section{S-containing RNAs in rnr1-3 contain additional endonucleolytic cleavages in vivo}

The in vitro-derived data presented above imply that pre$5 \mathrm{~S}$ rRNAs are targets for AS5-mediated turnover, especially in $r n r 1$. S1 nuclease protection was used to search for in vivo evidence of AS5-mediated pre-5S rRNA cleavage. A 5 '-end-labeled 417-nt ssDNA probe (Fig. 8A) was hybridized to total RNA from WT or rnr1-3, or to yeast tRNA as a negative control, digested with $\mathrm{S} 1$ nuclease, and analyzed

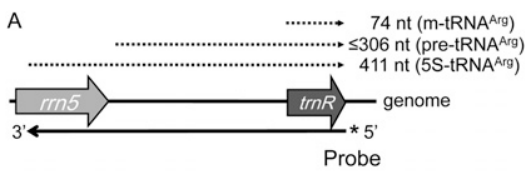

B

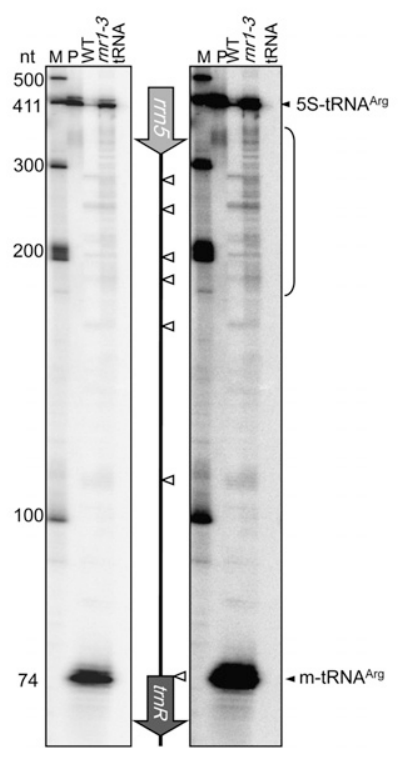

FIGURE 8. S1 nuclease protection of tRNA ${ }^{\text {Arg }}$ precursors generated in vivo. (A) The 5S-trnR region of the chloroplast genome and the positions of protected fragments (dashed lines) observed in panel $B$. The $5^{\prime}$-labeled probe is shown below the diagram. (B) S1 nuclease protection. (Lane M) markers; (lane P) probe alone; (lanes WT and rnr1-3) protection using total RNA; (lane tRNA) negative control using yeast tRNA. Electrophoresis was in a $6 \%$ polyacrylamide gel, which is shown in two exposures. Open arrowheads indicate the positions of $5^{\prime}$ ends that are present both in the WT and rnr1-3.

by gel electrophoresis (Fig. $8 \mathrm{~B}$ ). In both WT and $r n r 1-3$ samples, the probe protected a 74-nt fragment representing mature $\mathrm{tRNA}^{\mathrm{Arg}}$ and a 411-nt fragment representing the 5S-tRNA ${ }^{\text {Arg }}$ co-transcript, the latter of which overaccumulated in rnr1-3 (Fig. 1). The probe also protected low levels of tRNA ${ }^{A r g}$ precursors, visible on the longer gel exposure at right, whose $5^{\prime}$ ends are generated by endonucleolytic cleavages within the $5 \mathrm{~S}$ intergenic region in both WT and rnr1-3 (Fig. 8B, open arrowheads), and which are likely substrates for RNase P. In addition, the probe protected numerous pre-tRNA ${ }^{\text {Arg }}$ transcripts exclusively in the $r n r 1-3$ sample, representing additional endonucleolytic cleavages within proximal region of the $r r n 5-t r n R$ intergenic region and the distal region of the $5 \mathrm{~S}$ coding sequence (Fig. 8B, bracket). We hypothesize that these additional cleavages result from AS5-stimulated targeting of an endoribonuclease to $5 \mathrm{~S}-\mathrm{trnR}$.

\section{RNase E and RNase J may mediate endonuclease cleavage within the $5 \mathrm{~S}$ intergenic region}

The S1 nuclease protection data presented above indicate that endonuclease cleavages occur within the $5 S-\operatorname{trn} R$ 
intergenic region during maturation of $5 \mathrm{~S}$ rRNA. Within higher plants, two chloroplast endonucleases have been identified, RNase E (Mudd et al. 2008) and RNase J (Olinares et al. 2010). RNase J also harbors 5' -to-3' exonuclease nuclease activity, based on studies of the Bacillus subtilis orthologs (for review, see Condon 2010). We wished to ascertain if plants deficient for these enzymes would exhibit abnormalities in 5S rRNA biogenesis, and compare them to previously studied exoribonuclease mutants $r n r 1$ and pnp, which lacks polynucleotide phosphorylase (Marchive et al. 2009).

As previously shown, the rne homozygous mutant is viable in Arabidopsis (Walter et al. 2010). RNase J1 is essential in B. subtilis, and, similarly, the Arabidopsis null allele of RNase $\mathrm{J}$ is unrecoverable as the mutant is embryolethal (http://www.seedgenes.org). Therefore, virus-induced gene silencing (VIGS) was used to generate knockdown material for RNase J, resulting in chlorotic leaf material (mutant phenotypes are shown in Supplemental Fig. S3).

Figure 9 shows the analysis of $5 \mathrm{~S}$ and trnR-containing transcripts in wild-type and mutant material. For 5S rRNA (Fig. 9A), WT contained only the mature species (band D), but the mutants accumulated the $5 \mathrm{~S}$-trnR precursor (bands A and, except pnp, B), the $5 \mathrm{~S}$ plus the intergenic spacer (band $\mathrm{C}$ ), and in the rne and rnrl mutants, previously

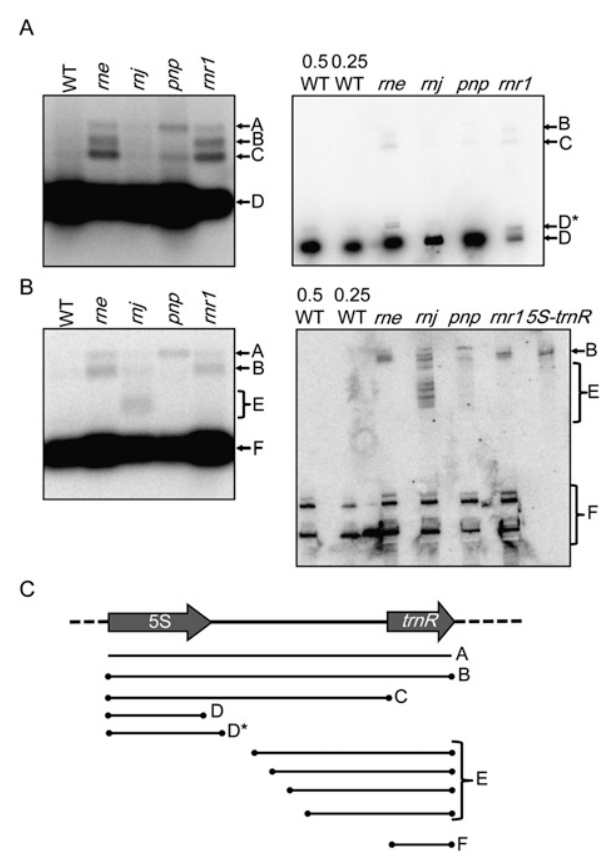

FIGURE 9. Analysis of $5 \mathrm{~S}$ rRNA $(A)$ or tRNA ${ }^{\text {Arg }}(B)$ processing in chloroplast RNase mutants. $(A, B)$ Gel blot analysis of total RNA extracted from WT, rne, $r n j$, pnp, and rnrl-3 rosette leaves, separated in agarose $(0.5 \mu \mathrm{g}$; left panels) or polyacrylamide ( $1.0 \mu \mathrm{g}$; right panels) gels. Relative loading of WT RNA is indicated above the blots. The right lane of the polyacrylamide gel in panel $B$ is an in vitro transcript to serve as a size marker for the $5 \mathrm{~S}$-trnR dicistronic transcript. (Bands A-F) Transcripts discussed in the text. $(C)$ Interpretation of bands observed in $A$ and $B$, as discussed in the text. described 5S rRNA with short $3^{\prime}$ extensions (band $\mathrm{D}^{\star}$ ). Bands $\mathrm{B}$ and $\mathrm{C}$ were most prominent in the rne and rnrl mutants, indicating that precursor processing efficiency had been reduced. Identical blots probed for transcripts containing $\operatorname{trnR}$ (Fig. 9B) verified the 5S-trnR precursor transcripts (bands A and B). Surprisingly, however, the trnR probe also identified a unique cluster of bands (labeled E) in RNase J-deficient material, most easily seen on the polyacrylamide gel blot. We interpret them as a variety of intermediates, perhaps resulting from the postulated initial endonucleolytic cleavage $10 \mathrm{nt}$ downstream from the $5 \mathrm{~S}$ coding sequence (see Discussion). Finally, mature trnR accumulated in all genotypes (band F). The fact that both $5 \mathrm{~S}$ rRNA and $\operatorname{trnR}$ accumulate in RNase E- and RNase Jdeficient materials suggests that the enzymes are likely to be partly redundant for their maturation.

\section{DISCUSSION}

We have previously ascribed the role of chloroplast rRNA 3'-end-maturation to the exoribonuclease RNR1, which may partner with PNPase in some cases. In the absence of RNR1, 5S rRNA transcripts are improperly processed and decrease in abundance, correlating with reduced ribosome assembly (Bollenbach et al. 2005). The finding that AS5, a naturally occurring RNA antisense to the $5 \mathrm{~S}$-trnR region, overaccumulates in $r n r 1-3$ and forms base-paired regions with $5 \mathrm{~S}$ - $t r n R$ sense transcripts in vitro, suggests this noncoding RNA (ncRNA) impacts 5S rRNA biogenesis and ultimately, ribosome assembly and/or translation. These findings introduce a potential new level of post-transcriptional regulation in chloroplasts. Apart from the implications for asRNA regulation of rRNA biogenesis, our data point to RNR1 as an enzyme that is involved in the turnover of at least one asRNA. Such a role for RNR1 in bacteria has not yet been described, to our knowledge. As shown in Figure 1, RNR1 deficiency also leads to overaccumulation of $t R N A^{A r g}$. RNase $\mathrm{R}$ in Escherichia coli has been shown to degrade structured RNAs efficiently (for review, see Andrade et al. 2009), so our results may point to RNR1 as a tRNAdegrading enzyme in chloroplasts.

\section{AS5: A plastid-encoded ncRNA}

Small ncRNAs are widespread, but until recently, their roles in gene regulation have been greatly underappreciated. Sequence analysis has revealed that, like their prokaryotic ancestors, chloroplasts and mitochondria accumulate numerous ncRNAs whose functions remain to be elucidated (Holec et al. 2006; Lung et al. 2006). In this study, we identified AS5 transcripts in the EST database for a number of plant species (Fig. 2A; data not shown). Arabidopsis AS5 ESTs range from 302 to $474 \mathrm{nt}$ and overlap the 5 S-trnR region to varying degrees. RNA gel blot analysis identified three main AS5 transcripts of $1.1-1.5 \mathrm{~kb}$ that overaccumulate 
in rnrl-3 plants compared to their WT counterparts, in agreement with qRT-PCR data (Fig. 2). While these are longer than the ESTs, two factors should be kept in mind. First, the ESTs were generated from transcripts containing poly(A) tails, which trigger RNA decay in chloroplasts (for review, see Schuster and Stern 2009). Therefore, the AS5 species identified by ESTs are most likely degradation intermediates of AS5, rather than the putative full-length species seen in the gel blots. Second, these ESTs represent sequences derived from the $3^{\prime}$ ends of longer molecules. Thus, the cDNA clones themselves are likely longer than the sequences deposited in GenBank. Finally, cRT-PCR identified three species of 400-474 nt. Because cRT may be biased toward shorter and/or less structured molecules that more readily circularize and are more easily amplified by PCR, this approach may have preferentially identified AS5 derivatives that had been cleaved following sense-strand interactions. We also cannot rule out that alternative AS5 promoters exist. For example, AS5 may be co-transcribed with $\operatorname{trn} N$ and/or have a promoter in the $\operatorname{trn} N-\operatorname{trn} R$ intergenic region (Fig. 2C). Clearly, AS5 represents a family of transcripts, and each of the methods we have used has identified a unique set. Determining the precise origins of each of these species will be important to our future understanding of chloroplast asRNA biogenesis and function.

\section{In vitro dissection of AS5 inhibitor sequences}

Using a chloroplast protein extract, we demonstrated that the $5 \mathrm{~S}$-trnR precursor is correctly processed and that the most inhibitory forms of AS5 of this processing, namely, AS5-1 and AS5-4, include sequences complementary to the $5 \mathrm{~S}$ rRNA and intergenic spacer. Previous studies in Brassica napus showed that the intergenic region is important for processing of 5S-trnR transcripts, by serving as a site of endonuclease cleavages that precede $3^{\prime}$-end trimming of pre-5S by RNR1 and/or PNPase (Leal-Klevezas et al. 2000). AS5-2 and AS5-5/6, which span the intergenic region but lack sequences antisense to the $5 \mathrm{~S}$ coding region, were not efficient inhibitors (Figs. 3 and 4). Similarly, AS5-3, antisense to the coding region only, was a relatively inefficient inhibitor. One possibility for the difference in inhibition by AS5-1 and AS5-4 is that their efficiencies differ in forming intermolecular base pairs with $5 \mathrm{~S}$ transcripts. A key trigger for the formation of analogous duplexes in prokaryotic systems is the "kissing complexes" that occur between singlestranded regions of sense and antisense RNAs (Persson et al. 1990; Tomizawa 1990). These interactions lead to further base-pairing, analogous to the MBN-resistant fragments of 5S-trnR identified in Figure 7.

Because the extent and locations of interactions between ncRNAs and their sense targets are important determinants of their biological activity, we used MBN to gauge regions of dsRNA formation between AS5 and its sense target and found that only a small fraction of transcripts were completely base-paired. This is particularly evident for AS5-1 and AS5-4 in Figure 7, where smaller protected fragments of the $5 S$-trnR substrate were far more abundant than the full-length duplex. The results also show that while relatively long regions of stable dsRNA are forming in these experiments, dsRNA formation is limited near the $+40-60$ nucleotide region, with respect to the $5 S$ rRNA $3^{\prime}$ end.

While our in vitro results support a mechanism whereby excess AS5 leads to decreased 5S rRNA abundance in rnrl, additional work would be required to unambiguously establish this causal relationship in vivo. Detection of presumably transient AS5-pre-5S duplexes in vivo, as well as identification of the ribonuclease activity that targets this duplex, will be of interest in the future. We also note that the in vitro experiments used molar ratios of precursor and asRNA that may not represent the ratios of the bioactive molecules in vivo. On the other hand, our recent demonstration that overexpression of AS5 in tobacco chloroplasts destabilizes the 5S rRNA (Hotto et al. 2010) supports the viewpoint that the in vitro system is a useful platform for dissecting the mechanism of AS5 action.

\section{Model describing the mechanism of AS5 regulation of $5 \mathrm{~S}$ rRNA biogenesis}

Regulatory ncRNAs can be classified as cis-encoded, where the ncRNA targets the corresponding sense-strand gene resulting in the possibility of complete base-pairing, and trans-encoded where ncRNAs are encoded far from their targets (Gottesman 2004). Cis regulation, as we have proposed here, is well characterized in several situations, for example, toxin-antitoxin systems where a cis asRNA can repress the toxin synthetic mRNA. These pairs operate by different mechanisms including occlusion of Shine-Dalgarno sequences and creation of duplexes subject to RNase III cleavage (for review, see Fozo et al. 2008; Waters and Storz 2009). Analogous duplexes can also be targeted by RNase E, through its assembly with the RNA chaperone Hfq (Morita et al. 2005).

Our working model for maturation of the $5 \mathrm{~S}$ - $\operatorname{trn} R$ region and the effects of AS5 overaccumulation are depicted in Figure 10. We posit that RNR1 plays a role in AS5 degradation, leading to its overabundance in $r n r 1$ mutants. In bacteria, RNase $\mathrm{R}$ is not a prominent regulator of ncRNAs, although it can degrade transcripts with strong secondary structures (Cheng and Deutscher 2005). Thus, involvement in asRNA turnover appears to be a new role for RNase R.

We hypothesize that AS5 interferes with the normal maturation of $5 \mathrm{~S}$ rRNA. Two steps that may be affected are endonucleolytic cleavages within the intergenic region, and $3^{\prime}$-exonucleolytic trimming. The endonucleolytic step also occurs in bacteria. In B. subtilis, it is carried out by RNase M5, which cleaves a dsRNA moiety in the 5S rRNA precursor (Condon et al. 2001). In E. coli, the substrate is a single-stranded segment that is cleaved by RNase E (Ghora 


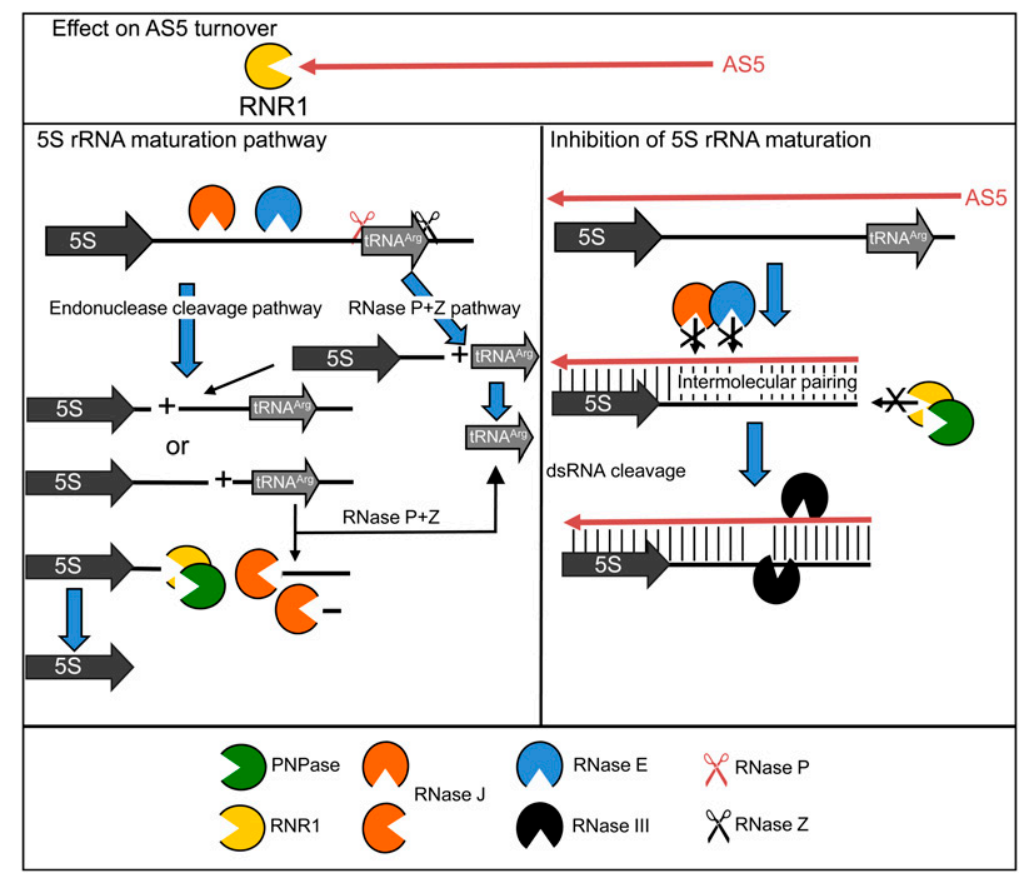

FIGURE 10. Model for AS5-mediated regulation of $5 S$ maturation. (Top) AS5 abundance is modulated by RNR1. (Left side) 5 S-trnR maturation is initiated by endonuclease cleavage either in the intergenic region by RNase $\mathrm{E}$ and/or J, or by RNase P. 5S-containing intermediates are trimmed by RNR1 and PNPase, whereas trnR-containing intermediates are trimmed $5^{\prime}$-to- $3^{\prime}$ by RNase J, or are subject to RNase P cleavage. The tRNA ${ }^{\mathrm{Arg}} 3^{\prime}$ end is created by RNase Z. (Right side) AS5 potentially regulates this maturation through either complete or partial duplexing with 5S rRNA precursors. This base-pairing would inhibit endonucleolytic cleavage downstream from the mature $5 S$ rRNA $3^{\prime}$ end, and create a target for RNase III-like enzymes that would trigger degradation of both sense and antisense strands.

and Apirion 1978), followed by $3^{\prime}$ trimming by the exoribonuclease RNase T ( $\mathrm{Li}$ and Deutscher 1995). Since the chloroplast RNase E catalytic domain has similar properties to the E. coli enzyme (Schein et al. 2008), it is not unlikely that this enzyme would be inhibited by duplex RNA arising from AS5. Indeed, the Arabidopsis rne-null mutant accumulates 5S-trnR precursors (Fig. 9), although clearly there is an RNase E-independent maturation pathway for $5 \mathrm{~S}$ rRNA. This could be initiated by RNase J, where deficient material also accumulates some $5 \mathrm{~S}$ precursors, by an exonucleolytic pathway following RNase $\mathrm{P}$ cleavage of tRNA ${ }^{\text {Arg }}$, or by other enzymes. The possible functional overlap of RNase J and RNase E is suggested by the fact that RNase J seems to replace at least some RNase E functions in B. subtilis (Britton et al. 2007).

A surprising result was the substantial accumulation of intergenic region-trnR precursors in RNase J-deficient material. We interpret this as defining a role for the putative 5'-to-3' exonuclease activity of chloroplast RNase J in degrading the intergenic region, and perhaps in assisting in the maturation of tRNA ${ }^{\mathrm{Arg}}$, which is not redundant with RNase E function (Fig. 9B).

A decrease in maturation efficiency alone would lead to overaccumulation of $5 \mathrm{~S}$ rRNA precursors, which only occurs to a limited extent in rnrl-3. Therefore, we hypothesize that AS5pre-5S duplexes are targeted by an RNase III-like enzyme, which would generate fragments subject to exonucleolytic decay. Arabidopsis encodes several prokaryotic RNase III-like enzymes that contain putative chloroplast-targeting sequences. Two of these genes, Atlg55140 and At3g13740, encode the RNase III catalytic domain and are members of the mini-III subfamily (Olmedo and Guzmàn 2008) that participates in rRNA maturation in B. subtilis (Redko et al. 2008). Another family member (At4g37510) appears to be catalytically inactive and involved in chloroplast RNA splicing, based on results from the maize ortholog (Watkins et al. 2007). Further work is required to ascertain if any of these enzymes has a role in asRNA function.

Although the role we ascribe to AS5 is accentuated in the rnrl mutant, we presume it would also operate in WT plants. The function of 5S rRNA in organelle ribosomes is still somewhat enigmatic. In prokaryotes, ribosome synthesis is tightly linked with transcription of rRNAs (Condon et al. 1995), and E. coli deletion mutants of $5 \mathrm{~S}$ rDNA have severe growth rate defects (Ammons et al. 1999), probably because large ribosomal subunits lacking 5S rRNA operate inefficiently (Dohme and Nierhaus 1976). The Arabidopsis rnr1-3 mutant showed a shift of chloroplast rRNAs toward non-polysomal fractions (Bollenbach et al. 2005), suggesting that 5S rRNA may also be required for optimal ribosome assembly or function in chloroplasts.

\section{MATERIALS AND METHODS}

\section{Plant growth and tissue}

Arabidopsis thaliana Col-0 WT, rnr1-3 (SALK_090294), pnp1-1 (SALK_013306), and rne (SALK_093546) plants were germinated and grown in MS-agar medium under fluorescent light (100 $\mu \mathrm{mol} \cdot \mathrm{m}^{-2} \cdot \mathrm{sec}^{-1}$ ) and a 16 -h-light/8-h-dark photoperiod. At $25 \mathrm{~d}$ post-germination, rne plants were transferred to soil and grown under $150 \mu \mathrm{mol} \cdot \mathrm{m}^{-2} \cdot \mathrm{sec}^{-1}$ light. Leaf tissue was harvested and flash-frozen in liquid nitrogen for subsequent analysis.

\section{Virus-induced gene silencing of Arabidopsis RNase J}

Primers At RNJ VIGS for and At RNJ VIGS rev were used to amplify a 160-bp product from a unique region of the Arabidopsis RNase J ortholog (At5g63420) as determined by CATMA 
(http://www.catma.org). The amplified DNA was inserted into pCR8/GW/TOPO (Invitrogen). Using LR Clonase (Invitrogen), the RNase J amplicon was inserted into pYL170GW (Burch-Smith et al. 2006). The pYL RNJ plasmid was transformed into Agrobacterium GV3101 by electroporation and plated on LB-agar containing $100 \mu \mathrm{g} / \mathrm{mL}$ rifampicin and $50 \mu \mathrm{g} / \mathrm{mL}$ kanamycin. Arabidopsis WT Col-0 plants were germinated in soil and grown under $100 \mu \mathrm{mol} \cdot \mathrm{m}^{-2} \cdot \mathrm{sec}^{-1}$ light to the 2-3 rosette leaf stage. Agrobacterium infiltration solution was prepared as described (Burch-Smith et al. 2006), and the final $\mathrm{OD}_{600}$ of Agrobacterium was adjusted to 1.5. All rosette leaves were infiltrated, and the plants were allowed to stand for $48 \mathrm{~h}$ in the laboratory before being returned to the growth chamber. Silenced material was harvested and flash-frozen in liquid nitrogen for subsequent analysis.

\section{RNA analysis}

RNA was isolated from leaves, roots, flowers/buds, and 14-d-old seedlings using Tri Reagent (Molecular Research Center; http:// www.mrcgene.com) according to the manufacturer's instructions. RNA was isolated from siliques and dried seeds as described (Vicient and Delseny 1999). Total RNA was separated in $12 \%$ polyacrylamide gels and transferred to nylon membranes (Hybond $\mathrm{N}^{+}$; GE Healthcare) or GeneScreen $\mathrm{N}$ membrane (Perkin-Elmer) in a semi-dry blot apparatus (GE Healthcare), or in $1.2 \%$ formaldehyde-agarose gels buffered by sodium phosphate $(\mathrm{pH}$ 6.8) and transferred to GeneScreen N. Blots derived from polyacrylamide gels were prehybridized in a $50 \%$ formamide buffer $(5 \times$ SSC, $2 \%$ [w/v] BSA, 0.6\% [w/v] SDS, $200 \mu \mathrm{g} / \mathrm{mL}$ salmon sperm DNA) for $>6 \mathrm{~h}$, while RNA blots derived from agarose gels were prehybridized in Church and Gilbert buffer (Church and Gilbert 1984). All blots were hybridized overnight at $65^{\circ} \mathrm{C}$. Signal intensity for each blot was measured on a Storm scanner (Molecular Dynamics). Uniformly labeled antisense RNA to probe blots for trnR was synthesized (see below) from the PCR product of the primer pair trnR qPCR5' and AS5 (T3).

\section{RT-PCR, qRT-PCR, and CRT-PCR}

To qualitatively determine AS5 accumulation by RT-PCR, cDNA was generated by Supercscript III (Invitrogen) from $0.5 \mu \mathrm{g}$ of RQ1 DNase-treated (Promega) total RNA using the AS5-specific reverse primer $\mathrm{P} 1$ and the reverse primer specific for UBQ10 (ubiquitin), UBQ2. AS5-containing cDNA was then amplified using 25 PCR cycles with primers P1 and P2. UBQ10 mRNA was amplified as a control (28 cycles) using the primers UBQ1 and UBQ2. All primer sequences are given in Supplemental Table S1.

To quantify the levels of $r r n 5, \operatorname{trnR}$, and AS5, $1 \mu \mathrm{g}$ of DNasetreated RNA was reverse-transcribed with SuperScript III using the $3^{\prime}$ qRT-PCR gene-specific primers, including those used for normalization mRNAs, according to the manufacturer's instructions. Separate cDNA synthesis reactions were completed for AS5 and the rrn5/trnR genes. The qRT-PCR reaction mix contained $1 \times$ Fast SYBR Green Master Mix (Applied Biosystems), 2 ng of cDNA, and $300 \mathrm{nM}$ each primer in a reaction volume of $20 \mu \mathrm{L}$. Amplification was done in a CFX96 real-time PCR detection system (Bio-Rad) using the following two-step cycling conditions: initial denaturation at $95^{\circ} \mathrm{C}$ for $3 \mathrm{~min}, 40$ cycles at $95^{\circ} \mathrm{C}$ for $10 \mathrm{sec}$, and $59^{\circ} \mathrm{C}$ for $30 \mathrm{sec}\left(+\right.$ plate read), and a final incubation at $95^{\circ} \mathrm{C}$ for $10 \mathrm{sec}$, after which a melt curve analysis was completed $\left(59^{\circ} \mathrm{C}-\right.$ $95^{\circ} \mathrm{C}$ in $0.5^{\circ} \mathrm{C}$ steps) to ensure amplification specificity. Quantification and primer efficiencies were determined by comparison to four-step standard curves (0.04-10.00 ng of cDNA in fivefold increments). Relative quantification compared to WT samples (given a reference value of 1 ) was achieved after normalization to the actin mRNA by the Bio-Rad CFX Manager software, taking into account differences in primer efficiencies.

The $5^{\prime}$ and $3^{\prime}$ ends of AS5 were determined by cRT-PCR as described previously (Perrin et al. 2004). Briefly, $0.5 \mu \mathrm{g}$ of total RNA was circularized using T4 RNA ligase (NEB), and cDNA spanning the junction of the $5^{\prime}$ - and $3^{\prime}$-ligated ends was generated using primer $\mathrm{P} 4$. This region was then amplified using primers $\mathrm{P} 3$ and $\mathrm{P} 4$, and the products were cloned and sequenced.

\section{Preparation of spinach chloroplast protein extract}

For in vitro RNA processing assays, soluble chloroplast extract was prepared from young spinach leaves as previously described (Gruissem et al. 1986).

\section{Construction of DNA templates for in vitro transcription}

The 5S-trnR, $5 \mathrm{~S}+\mathrm{I}, 5 \mathrm{~S}+33$, and 5S DNA templates were amplified from Arabidopsis plastid DNA using the primer pairs 5S-trnR F (T7)/P2, 5S-trnR F (T7)/5S inter R, 5S-trnR F (T7)/ 5S-33 R, and 5S-trnR F (T7)/5S 108069, respectively, and each included the T7 promoter sequence. The AS5-1-AS5-7 DNA templates were amplified from Arabidopsis DNA using the primer pairs AS1 (T3)/P1, AS2 (T3)/AS3, AS4 (T7)/P1, AS5 (T3)/P1, AS5 (T3)/ AS3, and AS2 (T3)/AS6 and equipped with the T3 or T7 promoter to synthesize the desired asRNA species.

\section{In vitro analysis of AS5 function and mung bean nuclease treatment}

Synthetic sense and antisense transcripts were synthesized using T7 and T3 polymerase (Promega) following the manufacturer's protocols. Sense 5S RNA substrates were uniformly labeled by adding $\left[{ }^{32} \mathrm{P}\right] \mathrm{UTP}(800 \mathrm{Ci} / \mathrm{mmol}$; Perkin Elmer) to $2.5 \mu \mathrm{M}$, and AS5 transcripts were trace-labeled by adding $\left[{ }^{32} \mathrm{P}\right] \mathrm{UTP}$ to 0.008 $\mu \mathrm{M}$. Transcripts were excised after separation in $5 \%$ denaturing polyacrylamide gels and eluted overnight at $4^{\circ} \mathrm{C}$ in $0.3 \mathrm{M} \mathrm{Na}$ acetate ( $\mathrm{pH} 7.0$ ), $0.05 \mathrm{M}$ EDTA ( $\mathrm{pH} 8.0$ ), and 2\% SDS.

For $5^{\prime}$-end-labeling, synthesis of the $5 \mathrm{~S}$-trnR transcript by $\mathrm{T} 7$ RNA polymerase was performed in the presence of $5 \mathrm{mM}$ unlabeled UTP. The $5^{\prime}$-end triphosphate was removed sequentially by first removing pyrophosphate by treatment with tobacco acid phosphatase (TAP; EPICENTRE Biotechnologies), followed by the addition of alkaline phosphatase (Promega) to remove remaining monophosphates. 5S-trnR transcripts were 5 '-end-labeled by polynucleotide kinase using $2 \mu \mathrm{L}$ of $\left[\gamma^{-}{ }^{32} \mathrm{P}\right] \mathrm{ATP}(3000 \mathrm{Ci} /$ mmol).

Preliminary experiments revealed that a ratio of 1 fmol of labeled RNA to $30 \mu \mathrm{g}$ of chloroplast protein provided optimal kinetics for studying asRNA inhibition of rRNA maturation (data not shown). For in vitro analysis, 1 fmol of radiolabeled 5Scontaining RNA was incubated in the absence or presence of 
50- to 1000-fold molar excess of trace-labeled asRNA in a final volume of $7 \mu \mathrm{L}$ for $30 \mathrm{~min}$ at $23^{\circ} \mathrm{C}$. Chloroplast protein was preequilibrated in $0.75 \mu \mathrm{L}$ of IVT buffer $\left(3.75 \mathrm{mM} \mathrm{MgCl}_{2}, 2 \mathrm{mM}\right.$ DTT, and $10 \mathrm{mM} \mathrm{KCl}$ ) for $10 \mathrm{~min}$ at $30^{\circ} \mathrm{C}$, after which RNA was added to a final concentration of $2 \mathrm{mg} / \mathrm{mL}$. The reactions $(15 \mu \mathrm{L})$ were incubated for $30 \mathrm{~min}$ at $30^{\circ} \mathrm{C}$, and terminated by adding stop solution ( $6 \mathrm{M}$ urea, $1 \% \mathrm{SDS}$, and $4.5 \mathrm{mM}$ aurintricarboxylic acid). RNA was extracted by adding phenol:chloroform:isoamyl alcohol $(24: 24: 1)$ in a $1: 1$ ratio and precipitated with 3 vol of ethanol and 0.1 vol of $3 \mathrm{M}$ sodium acetate ( $\mathrm{pH}$ 5.2). For isolating RNA from in vitro reactions under native conditions, $35 \mu \mathrm{L}$ of $1 \times$ IVT buffer was added to each reaction followed by addition of an equal volume of phenol:chloroform:isoamyl alcohol (24:24:1). RNA was precipitated as above and resuspended in $13.5 \mu \mathrm{L}$ of $\mathrm{H}_{2} \mathrm{O}$ before addition of $1.5 \mu \mathrm{L}$ of $10 \times$ mung bean nuclease buffer (Promega). Where indicated, reaction products were treated with $170 \mathrm{U}$ of mung bean nuclease either by directly adding enzyme to the reaction for $15 \mathrm{~min}$, or by treating purified RNA reaction products for $10 \mathrm{~min}$ at $30^{\circ} \mathrm{C}$.

\section{S1 nuclease protection}

To prepare probes, the region spanning $5 \mathrm{~S}$ and $\operatorname{trn} R$ ( $5 \mathrm{~S}$-trnR) was amplified with primers $\mathrm{P} 1$ and $\mathrm{P} 2$. The resulting PCR product was resuspended in $10 \mathrm{mM}$ Tris- $\mathrm{HCl}(\mathrm{pH} 9.5), 1 \mathrm{mM}$ EDTA, $1 \mathrm{mM}$ spermidine at a concentration of $1 \mathrm{pmol} / \mu \mathrm{L}$, and incubated for $2 \mathrm{~min}$ at $95^{\circ} \mathrm{C}$. The reaction was placed on ice, and $0.1 \mathrm{vol}$ of $10 \times$ T4 polynucleotide kinase buffer, $2 \mu \mathrm{L}$ of $\left[\gamma^{-32} \mathrm{P}\right]$ ATP $(3000 \mathrm{Ci} /$ $\mathrm{mmol}$ ), and $10 \mathrm{U}$ of $\mathrm{T} 4$ polynucleotide kinase were added. The final volume of the labeling reaction was $20 \mu \mathrm{L}$. Following a 1-h incubation at $37^{\circ} \mathrm{C}$, the reaction was diluted to $40 \mu \mathrm{L}$, and unincorporated nucleotides were removed. The resulting endlabeled PCR product was then digested with AvrII $(0.4 \mathrm{U} / \mu \mathrm{L})$, and the single-stranded probe was gel-purified.

For S1 nuclease protection, $5 \mu \mathrm{g}$ of total RNA from WT or rnrl-3 was incubated in $80 \%$ formamide, $40 \mathrm{mM}$ PIPES, $400 \mathrm{mM}$ $\mathrm{NaCl}, 1 \mathrm{mM}$ EDTA, and $2.5 \times 10^{4} \mathrm{cpm}$ probe for $5 \mathrm{~min}$ at $95^{\circ} \mathrm{C}$, followed by overnight incubation at $42^{\circ} \mathrm{C}$. Samples were diluted with $300 \mu \mathrm{L}$ of $1 \times \mathrm{S} 1$ nuclease buffer containing $150 \mathrm{U}$ of S1 nuclease (Promega) and incubated for $45 \mathrm{~min}$ on ice followed by phenol:chloroform:isoamyl alcohol (24:24:1) extraction and ethanol precipitation.

\section{ACCESSION NUMBERS}

The Arabidopsis seed stocks were obtained from the Arabidopsis Biological Resource Center (http://abrc.osu.edu/): rnr1-3 (SALK_ 090294), pnp1-1 (SALK_013306), rne (SALK_093546).

\section{SUPPLEMENTAL MATERIAL}

Supplemental material can be found at http://www.rnajournal.org.

\section{ACKNOWLEDGMENTS}

We thank Arnaud Germain for the photograph of $p n p 1-1$ shown in Supplemental Figure S3. This work was supported by award DE-FG02-90ER20015 from the DOE Energy Biosciences Program.
Authors' contributions: The experiments were conceived by T.J.B., R.E.S., A.M.H., and D.B.S., and then performed by R.E.S., T.J.B., and A.M.H. The manuscript was prepared by R.E.S., T.J.B., A.M.H., and D.B.S.

Received June 24, 2010; accepted November 8, 2010.

\section{REFERENCES}

Ammons D, Rampersad J, Fox GE. 1999. 5S rRNA gene deletions cause an unexpectedly high fitness loss in Escherichia coli. Nucleic Acids Res 27: 637-642.

Andrade JM, Pobre Vn, Silva IJ, Domingues S, Arraiano CM, Ciaran C. 2009. The role of $3^{\prime}-5^{\prime}$ exoribonucleases in RNA degradation. In Progress in molecular biology and translational science, Vol. 85, pp. 187-229. Academic Press, New York.

Bollenbach TJ, Lange H, Gutierrez R, Erhardt M, Stern DB, Gagliardi D. 2005. RNR1, a $3^{\prime}-5^{\prime}$ exoribonuclease belonging to the RNR superfamily, catalyzes $3^{\prime}$ maturation of chloroplast ribosomal RNAs in Arabidopsis thaliana. Nucleic Acids Res 33: 2751-2763.

Bollenbach TJ, Sharwood RE, Gutierrez R, Lerbs-Mache S, Stern DB. 2009. The RNA-binding proteins CSP4la and CSP41b may regulate transcription and translation of chloroplast-encoded RNAs in Arabidopsis. Plant Mol Biol 69: 541-552.

Britton RA, Wen T, Schaefer L, Pellegrini O, Uicker WC, Mathy N, Tobin C, Daou R, Szyk J, Condon C. 2007. Maturation of the $5^{\prime}$ end of Bacillus subtilis 16S rRNA by the essential ribonuclease YkqC/RNase J1. Mol Microbiol 63: 127-138.

Burch-Smith TM, Schiff M, Liu Y, Dinesh-Kumar SP. 2006. Efficient virus-induced gene silencing in Arabidopsis. Plant Physiol 142: 2127.

Canino G, Bocian E, Barbezier N, Echeverria M, Forner J, Binder S, Marchfelder A. 2009. Arabidopsis encodes four tRNase Z enzymes. Plant Physiol 150: 1494-1502.

Cheng ZF, Deutscher MP. 2005. An important role for RNase R in mRNA decay. Mol Cell 17: 313-318.

Church G, Gilbert W. 1984. Genomic sequencing. Proc Natl Acad Sci 81: 1991-1995.

Condon C. 2010. What is the role of RNase J in mRNA turnover? RNA Biol 7: 316-321.

Condon C, Squires C, Squires CL. 1995. Control of rRNA transcription in Escherichia coli. Microbiol Rev 59: 623-645.

Condon C, Brechemier-Baey D, Beltchev B, Grunberg-Manago M, Putzer H. 2001. Identification of the gene encoding the 5S ribosomal RNA maturase in Bacillus subtilis: mature 5S rRNA is dispensable for ribosome function. RNA 7: 242-253.

Dohme F, Nierhaus KH. 1976. Role of 5S RNA in assembly and function of the 50S subunit from Escherichia coli. Proc Natl Acad Sci 73: 2221-2225.

Fozo EM, Hemm MR, Storz G. 2008. Small toxic proteins and the antisense RNAs that repress them. Microbiol Mol Biol Rev 72: 579589.

Georg J, Honsel A, Voss B, Rennenberg H, Hess WR. 2010. A long antisense RNA in plant chloroplasts. New Phytol 186: 615622.

Ghora BK, Apirion D. 1978. Structural analysis and in vitro processing to p5 rRNA of a 9S RNA molecule isolated from an rne mutant of E. coli. Cell 15: 1055-1066.

Gobert A, Gutmann B, Taschner A, Gossringer M, Holzmann J, Hartmann RK, Rossmanith W, Giege P. 2010. A single Arabidopsis organellar protein has RNase P activity. Nat Struct Mol Biol 17: $740-744$.

Gottesman S. 2004. The small RNA regulators of Escherichia coli: Roles and mechanisms. Annu Rev Microbiol 58: 303-328.

Gruissem W, Zurawski G. 1985a. Analysis of promoter regions for the spinach chloroplast $r b c L$, atpB and $p s b A$ genes. EMBO J 4: 33753383. 
Gruissem W, Zurawski G. 1985b. Identification and mutational analysis of the promoter for a spinach chloroplast transfer RNA gene. EMBO J 4: 1637-1644.

Gruissem W, Greenberg BM, Zurawski G, Prescott DM, Hallick RB. 1983. Biosynthesis of chloroplast transfer RNA in a spinach chloroplast transcription system. Cell 35: 815-828.

Gruissem W, Greenberg BM, Zurawski G, Hallick RB. 1986. Chloroplast gene expression and promoter identification in chloroplast extracts. Methods Enzymol 118: 253-270.

Hayes R, Kudla J, Schuster G, Gabay L, Maliga P, Gruissem W. 1996. Chloroplast mRNA 3'-end processing by a high molecular weight protein complex is regulated by nuclear encoded RNA binding proteins. EMBO J 15: 1132-1141.

Hegeman CE, Halter CP, Owens TG, Hanson MR. 2005. Expression of complementary RNA from chloroplast transgenes affects editing efficiency of transgene and endogenous chloroplast transcripts. Nucleic Acids Res 33: 1454-1464.

Holec S, Lange H, Kuhn K, Alioua M, Borner T, Gagliardi D. 2006. Relaxed transcription in Arabidopsis mitochondria is counterbalanced by RNA stability control mediated by polyadenylation and polynucleotide phosphorylase. Mol Cell Biol 26: 2869-2876.

Hotto AM, Huston ZE, Stern DB. 2010. Overexpression of a natural chloroplast-encoded antisense RNA in tobacco destabilizes $5 \mathrm{~S}$ rRNA and retards plant growth. BMC Plant Biol 10: 213. doi: 10.1186/1471-2229-10-213.

Ingle J. 1968. The effect of light and inhibitors on chloroplast and cytoplasmic RNA synthesis. Plant Physiol 43: 1850-1854.

Komine Y, Kwong L, Anguera MC, Schuster G, Stern DB. 2000. Polyadenylation of three classes of chloroplast RNA in Chlamydomonas reinhardtii. RNA 6: 598-607.

Kudla J, Hayes R, Gruissem W. 1996. Polyadenylation accelerates degradation of chloroplast mRNA. EMBO J 15: 7137-7146.

Leal-Klevezas DS, Martinez-Soriano JP, Nazar RN. 2000. Cotranscription of 5S rRNA-tRNA ${ }^{\text {Arg }}$ (ACG) from Brassica napus chloroplasts and processing of their intergenic spacer. Gene 253: 303-311.

Leaver CJ. 1973. Molecular integrity of chloroplast ribosomal ribonucleic acid. Biochem J 135: 237-240.

Li Z, Deutscher MP. 1995. The tRNA processing enzyme RNase T is essential for maturation of 5S RNA. Proc Natl Acad Sci 92: 68836886.

Lung B, Zemann A, Madej MJ, Schuelke M, Techritz S, Ruf S, Bock R, Hüttenhofer A. 2006. Identification of small non-coding RNAs from mitochondria and chloroplasts. Nucleic Acids Res 34: 38423852 .

Marchive C, Yehudai-Resheff S, Germain A, Fei Z, Jiang X, Judkins J, Wu H, Fernie AR, Fait A, Stern DB. 2009. Abnormal physiological and molecular mutant phenotypes link chloroplast polynucleotide phosphorylase to the phosphorus deprivation response in Arabidopsis. Plant Physiol 151: 905-924.

Morita T, Maki K, Aiba H. 2005. RNase E-based ribonucleoprotein complexes: mechanical basis of mRNA destabilization mediated by bacterial noncoding RNAs. Genes Dev 19: 2176-2186.

Mudd EA, Sullivan S, Gisby MF, Mironov A, Kwon CS, Chung WI, Day A. 2008. A $125 \mathrm{kDa}$ RNase E/G-like protein is present in plastids and is essential for chloroplast development and autotrophic growth in Arabidopsis. J Exp Bot 59: 2597-2610.

Mullet JE. 1988. Chloroplast development and gene expression. Annu Rev Plant Physiol Plant Mol Biol 39: 475-502.

Nishimura Y, Kikis EA, Zimmer SL, Komine Y, Stern DB. 2004. Antisense transcript and RNA processing alterations suppress instability of polyadenylated mRNA in Chlamydomonas chloroplasts. Plant Cell 16: 2849-2869.

Olinares PD, Ponnala L, van Wijk KJ. 2010. Megadalton complexes in the chloroplast stroma of Arabidopsis thaliana characterized by size exclusion chromatography, mass spectrometry, and hierarchical clustering. Mol Cell Proteomics 9: 1594-1615.
Olmedo G, Guzmàn P. 2008. Processing precursors with RNase III in plants. Plant Sci 175: 741-746.

Perrin R, Lange H, Grienenberger JM, Gagliardi D. 2004. AtmtPNPase is required for multiple aspects of the $18 \mathrm{~S}$ rRNA metabolism in Arabidopsis thaliana mitochondria. Nucleic Acids Res 32: 51745182.

Persson C, Wagner EG, Nordstrom K. 1990. Control of replication of plasmid R1: formation of an initial transient complex is ratelimiting for antisense RNA-target RNA pairing. EMBO J 9: 37773785.

Redko Y, Bechhofer DH, Condon C. 2008. Mini-III, an unusual member of the RNase III family of enzymes, catalyses $23 \mathrm{~S}$ ribosomal RNA maturation in B. subtilis. Mol Microbiol 68: 1096-1106.

Schein A, Sheffy-Levin S, Glaser F, Schuster G. 2008. The RNase E/Gtype endoribonuclease of higher plants is located in the chloroplast and cleaves RNA similarly to the E. coli enzyme. RNA 14: 10571068.

Schuster G, Gruissem W. 1991. Chloroplast mRNA 3' end processing requires a nuclear-encoded RNA-binding protein. EMBO J 10: 1493-1502.

Schuster G, Stern D. 2009. RNA polyadenylation and decay in mitochondria and chloroplasts. Prog Mol Biol Transl Sci 85: 393-422.

Slomovic S, Laufer D, Geiger D, Schuster G. 2005. Polyadenylation and degradation of human mitochondrial RNA: The prokaryotic past leaves its mark. Mol Cell Biol 25: 6427-6435.

Srivastava AK, Schlessinger D. 1990. Mechanism and regulation of bacterial ribosomal RNA processing. Annu Rev Microbiol 44: 105129.

Stern DB, Gruissem W. 1987. Control of plastid gene expression: 3' inverted repeats act as mRNA processing and stabilizing elements, but do not terminate transcription. Cell 51: 1145-1157.

Stern DB, Gruissem W. 1989. Chloroplast mRNA 3' end maturation is biochemically distinct from prokaryotic mRNA processing. Plant Mol Biol 13: 615-625.

Stern DB, Goldschmidt-Clermont M, Hanson MR. 2010. Chloroplast RNA metabolism. Annu Rev Plant Biol 61: 125-155.

Strittmatter G, Gozdzicka-Jozefiak A, Kossel H. 1985. Identification of an rRNA operon promoter from Zea mays chloroplasts which excludes the proximal tRNA ${ }_{\mathrm{GAC}}^{\mathrm{Val}}$ from the primary transcript. EMBO J 4: 599-604.

Tomizawa J-I. 1990. Control of colE1 plasmid replication: Intermediates in the binding of RNA I and RNA II. J Mol Biol 212: 683694.

van Vliet AH, Wren BW. 2009. New levels of sophistication in the transcriptional landscape of bacteria. Genome Biol 10: 233. doi: 10.1186/gb-2009-10-8-233.

Vicient CM, Delseny M. 1999. Isolation of total RNA from Arabidopsis thaliana seeds. Anal Biochem 268: 412-413.

Walter M, Kilian J, Kudla J. 2002. PNPase activity determines the efficiency of mRNA 3 '-end processing, the degradation of tRNA and the extent of polyadenylation in chloroplasts. EMBO $J$ 21: 6905-6914.

Walter M, Piepenburg K, Schöttler MA, Petersen K, Kahlau S, Tiller N, Drechsel O, Weingartner M, Kudla J, Bock R. 2010. Knockout of the plastid RNase E leads to defective RNA processing and chloroplast ribosome deficiency. Plant J 64: 851-863.

Waters LS, Storz G. 2009. Regulatory RNAs in bacteria. Cell 136: 615628.

Watkins KP, Kroeger TS, Cooke AM, Williams-Carrier RE, Friso G, Belcher SE, van Wijk KJ, Barkan A. 2007. A ribonuclease III domain protein functions in Group II intron splicing in maize chloroplasts. Plant Cell 19: 2606-2623.

Yehudai-Resheff S, Hirsh M, Schuster G. 2001. Polynucleotide phosphorylase functions as both an exonuclease and a poly(A) polymerase in spinach chloroplasts. Mol Cell Biol 21: 5408-5416. 

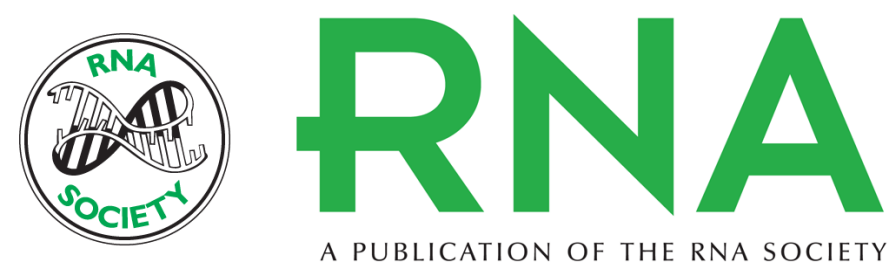

A PUBLICATION OF THE RNA SOCIETY

\section{Overaccumulation of the chloroplast antisense RNA AS5 is correlated with decreased abundance of $5 S$ rRNA in vivo and inefficient $5 S$ rRNA maturation in vitro}

Robert E. Sharwood, Amber M. Hotto, Thomas J. Bollenbach, et al.

RNA 2011 17: 230-243 originally published online December 9, 2010 Access the most recent version at doi:10.1261/rna.2336611

Supplemental Material

References

License

Email Alerting Service
http://rnajournal.cshlp.org/content/suppl/2010/11/24/rna.2336611.DC1

This article cites 59 articles, 21 of which can be accessed free at: http://rnajournal.cshlp.org/content/17/2/230.full.html\#ref-list-1

Receive free email alerts when new articles cite this article - sign up in the box at the top right corner of the article or click here. 